Article

\title{
An Ab Initio and Kinetic Monte Carlo Simulation Study of Lithium Ion Diffusion on Graphene
}

\author{
Kehua Zhong ${ }^{1,3, *}$, Yanmin Yang ${ }^{1,3}$, Guigui Xu ${ }^{1,2}$, Jian-Min Zhang ${ }^{1,3}$ and Zhigao Huang ${ }^{1,3, *}$ \\ 1 Fujian Provincial Key Laboratory of Quantum Manipulation and New Energy Materials, College of Physics \\ and Energy, Fujian Normal University, Fuzhou 350117, China; yym@fjnu.edu.cn (Y.Y.); \\ xuguigui82@126.com (G.X.); jmzhang@fjnu.edu.cn (J.-M.Z.) \\ 2 Concord University College, Fujian Normal University, Fuzhou 350117, China \\ 3 Fujian Provincial Collaborative Innovation Center for Optoelectronic Semiconductors and Efficient Devices, \\ Xiamen 361005, China \\ * Correspondence: khzhong@fjnu.edu.cn (K.Z.); zghuang@fjnu.edu.cn (Z.H.); \\ Tel./Fax: +86-591-22867577 (Z.H.)
}

Received: 15 June 2017; Accepted: 4 July 2017; Published: 6 July 2017

\begin{abstract}
The $\mathrm{Li}^{+}$diffusion coefficients in $\mathrm{Li}^{+}$-adsorbed graphene systems were determined by combining first-principle calculations based on density functional theory with Kinetic Monte Carlo simulations. The calculated results indicate that the interactions between $\mathrm{Li}$ ions have a very important influence on lithium diffusion. Based on energy barriers directly obtained from first-principle calculations for single- $\mathrm{Li}^{+}$and two- $\mathrm{Li}^{+}$adsorbed systems, a new equation predicting energy barriers with more than two Li ions was deduced. Furthermore, it is found that the temperature dependence of $\mathrm{Li}^{+}$diffusion coefficients fits well to the Arrhenius equation, rather than meeting the equation from electrochemical impedance spectroscopy applied to estimate experimental diffusion coefficients. Moreover, the calculated results also reveal that $\mathrm{Li}^{+}$concentration dependence of diffusion coefficients roughly fits to the equation from electrochemical impedance spectroscopy in a low concentration region; however, it seriously deviates from the equation in a high concentration region. So, the equation from electrochemical impedance spectroscopy technique could not be simply used to estimate the $\mathrm{Li}^{+}$diffusion coefficient for all $\mathrm{Li}^{+}$-adsorbed graphene systems with various $\mathrm{Li}^{+}$ concentrations. Our work suggests that interactions between $\mathrm{Li}$ ions, and among $\mathrm{Li}$ ion and host atoms will influence the $\mathrm{Li}^{+}$diffusion, which determines that the $\mathrm{Li}^{+}$intercalation dependence of $\mathrm{Li}^{+}$ diffusion coefficient should be changed and complex.
\end{abstract}

Keywords: graphene; diffusion coefficients of Li ion; first-principle calculations; Kinetic Monte Carlo

\section{Introduction}

Despite the comprehensive commercial use of C-based materials as the negative electrode in Li-ion batteries for a long time, its electronic and ionic transport properties are not understood well. These fundamental transport properties are very important for designing high power and energy density Li-ion batteries. Graphene is one of the most important C-based negative electrode materials. It is a two-dimensional (2D) film containing carbon atoms with honeycomb lattice [1]. It has many interesting physical properties, such as quantum electronic transport [2], massless Dirac fermions [3] and quantum anomalous hall effect [4], and has potential applications in physics, chemistry, energy and so on. Therefore, it has attracted a lot of research interest around the world since it was found in 2004 [5]. One of its many important applications is the potential application on $\mathrm{Li}$ ion batteries and other electrochemical storage devices [6-9]. Experimental results have demonstrated that graphene nanosheets have a good cyclic performance, and its specific capacity can reach $460 \mathrm{~mA} \mathrm{~h} \mathrm{~g}{ }^{-1}$ after 100 cycles [10]. Due to its high lithium storage capacity, good chemical stability, high conductivity, 
and good mechanical flexibility, graphene has been considered to be a suitable electrode alternative of battery [11,12].

Lithium-ion diffusion coefficient is a very important parameter in determining how fast a lithium ion battery can be cycled. Moreover, its determination will contribute to understanding the ionic transport mechanism in batteries. Several reports have showed that there are many techniques [13-19] to estimate the diffusion coefficient of ions. Among them, electrochemical impedance spectroscopy (EIS) $[16,17]$ is considered as a very powerful technique that is often used in experiments. In EIS technique, the chemical diffusion coefficient is calculated based on the solution of the Warburg impedance response [20-22]. However, unfortunately, because there are many experimental factors affecting the Lithium-ion diffusion coefficient in a battery, along with the extremely complex analysis of experimental data, the reported experimental results for diffusion coefficients of lithium ions vary a lot. For example, for a variety of composite-graphite electrode architectures, lithium-ion diffusion coefficients have been reported to vary from $10^{-6} \mathrm{~cm}^{2} \mathrm{~s}^{-1}$ to $10^{-16} \mathrm{~cm}^{2} \mathrm{~s}^{-1}$ [23-31].

Theoretically, using the density functional theory (DFT) method, Tachikawa [32] studied the lithium ion diffusion on a fluorine terminated graphene surface. The result showed that at around room temperature the Li ion moved freely on the surface, but it did not move towards the edge of surface. Deya et al. investigated the role of nitrogen and boron doping on $\mathrm{Li}$ ion diffusion along the vertical direction of defective graphene by using first-principles calculations to evaluate the energy barrier [33]. They found that the atomic doping would reduce the energy barrier. Uthaisar et al. [34] investigated $\mathrm{Li}$ atoms diffusion on the graphene and graphene nanoribbons by means of density functional theory. They found that Li adatoms would diffuse toward the edges while Li diffusion channels appear along the ribbon axis and their energy barriers were smaller than those on graphene. Some researchers $[35,36]$ have devoted their study to Li diffusion on pristine and defective graphene in both directions perpendicular and parallel to graphene using first-principles calculations. It is found that defects would bring down the energy barrier in the vertical direction of graphene nanosheets and consequently enhance the diffusion of Li. However, even though there have been many studies on Li diffusion in graphene, they basically focus solely on the diffusion behavior of a single particle without considering inter-particle interaction. In fact, the interaction between particles is always present, which must affect Li diffusion processes. Furthermore, due to the absence of dependable experimental techniques and theoretical methods, Li diffusion in graphene is still not understood well.

To effectively simulate the time evolution of a system, Kinetic Monte Carlo (KMC) simulation is designed. Taking the energy barriers from DFT calculations as input parameters, KMC simulation has been used to research atom desorption/adsorption processes on the surface [37], atom diffusion in bulk $[38,39]$, and so on. In this work, we study the diffusion coefficient of lithium ion in $\mathrm{Li}^{+}$-adsorbed graphene systems by combining first-principle calculations with KMC simulations, and mainly investigate the impacts of $\mathrm{Li}^{+}$concentration and temperature on the diffusion coefficients of $\mathrm{Li}^{+}$. Especially, the interactions between $\mathrm{Li}$ ions are considered. Once interactions between $\mathrm{Li}$ ions are taken into consideration, due to its sensitive dependence of near atom environment, the $\mathrm{Li}^{+}$migration energy barrier might change at any time in $\mathrm{Li}^{+}$s migration process. Thus, it is hard to get the energy barriers momentarily. However, $\mathrm{Li}^{+}$migration energy barriers used as input parameters in $\mathrm{KMC}$ simulations must be obtained to assess the diffusion coefficient of a lithium ion. To estimate the energy barriers in $\mathrm{Li}^{+}$'s migration process well, based on the energy barriers obtained from first-principle calculations for single- $\mathrm{Li}^{+}$and two- $\mathrm{Li}^{+}$adsorbed systems, we deduce a new equation to evaluate the energy barriers for $\mathrm{Li}^{+}$-adsorbed systems with more than two $\mathrm{Li}$ ions. Moreover, according to the above-calculated energy barriers and $\mathrm{KMC}$, the temperature and concentration dependences of diffusion coefficients of $\mathrm{Li}^{+}$were studied. The calculated results mean that the temperature dependence of the acquired diffusion coefficients of $\mathrm{Li}^{+}$were fitted to the Arrhenius equation, rather than meeting that from EIS technique, which had usually been used to estimate diffusion coefficients in experiments. At the same time, we also found that the $\mathrm{Li}^{+}$concentration dependence of the calculated diffusion coefficients of $\mathrm{Li}^{+}$also did not fully conform to that expected from the EIS technique. 


\section{Methods}

In our work, the first-principle calculations were implemented by using Vienna ab initio simulation package (VASP), and the projector augmented wave method was considered in the electron-ion interactions [40-46]. The exchange-correlation energy was calculated based on Perdew-Burke-Ernzerhof (PBE) [47] formulation of generalized gradient approximation (GGA) [40]. The cut-off energy was chosen as $450 \mathrm{eV}$. Considering the magnetism of the Li ion, the spin polarization was included. By the calculations, the lattice constant for graphene was obtained to be $2.459 \AA$, which is near the experimental value of $2.46 \AA$. A $3 \times 3 \times 1$ Monkhorst-Pack $k$-mesh was used for $7 \times 7 \times 1$ supercell of graphene primitive cell. Moreover, a vacuum separation of $18 \AA$ was employed to avert the artificial coupling role between neighboring layers. The geometry optimizations were implemented until the force acting on each atom was less than $0.02 \mathrm{eV} / \AA$. To study Li ion kinetics on graphene, the total energies along the possible diffusion pathways were calculated, and the diffusion barriers of Li ion were estimated as the energy difference between the configurations in which the Li ion was placed at the initial position and the most unstable position on the diffusion pathway $[35,48]$. The diffusion barrier was applied to estimate the macroscopic $\mathrm{Li}^{+}$diffusion coefficient on graphene using KMC simulations.

The detailed KMC algorithm follows the conventional procedure [49,50]. In the KMC simulation, the transition state theory (TST) is applied to describe the influences of interactions among neighboring Li ions and temperature. According to TST, an ion's migration from an initial site to its adjacent vacancy is achieved by experiencing a transition state. There is an energy barrier $E_{\mathrm{m}}$ separating the two corresponding states before and after migration. The migration of the Li ions follows the general KMC procedures: (1) Determine all possible migration sites. With regard to the current atomic configuration, the first-nearest-neighbor vacant sites were considered as possible migration sites. (2) Identify a series of the transition rates $\left(p_{\mathrm{i}}\right)$ for all possible migration states. Based on TST theory, the transition rate is defined as follows [51,52]:

$$
p_{\mathrm{i}}=p \exp \left(-E_{\mathrm{m}} / k_{\mathrm{B}} T\right),
$$

where, the preexponential factor $p=2 k_{\mathrm{B}} T / h$ is the jump frequency. $E_{\mathrm{m}}$ denotes the migration energy barrier which can be obtained from the first-principle calculations. $h, k_{\mathrm{B}}$, and T are Planck's constant, the Boltzmann constant and temperature $(K)$, respectively. (3) Calculate a accumulation $P_{\mathrm{j}}=\sum_{\mathrm{i}=1}^{\mathrm{j}} p_{\mathrm{i}}$, with $j=1, \ldots, n$ at the current position of a selected $\mathrm{Li}^{+}$, respectively. Here, $n$ denotes the total number of the possible jumping sites. In fact, $j$ does also mean $j$ th jumping direction. As the neighboring site is occupied, a zero transition rate is set. Next, a uniform random number $u$ from the interaval $[0,1]$ is drawn, and then the $j$ th jumping direction was selected according to $P_{\mathrm{j}-1}<u P_{\mathrm{n}}<P_{\mathrm{j}}$. Thus, the migration event was generated, and the change of its neighbors caused by migration was then updated. Then the simulation moves into the next step. At each step of the algorithm, the simulation time $t$ is incremented by $\Delta t$ which is given by

$$
\Delta t=-P_{\mathrm{n}}^{-1} \ln u
$$

In KMC simulation, according to the Einstein relation the diffusion coefficient could be decided by: $[51,52]$

$$
D=\lim _{\mathrm{t} \rightarrow \infty} \frac{<r(\mathrm{t})^{2}>}{4 t},
$$

where $t$ is the simulation time and $\left\langle r(\mathrm{t})^{2}>\right.$ is the mean squared displacement of Li. Each KMC simulation step contains $N_{\mathrm{Li}}$ steps $\left(N_{\mathrm{Li}}\right.$ is the total number of Li ions), and the mean squared displacement is the average for all $\mathrm{Li}$ ions. The sum of all time increments for each jump is defined as the total time increment. 
Graphene is a single atomic layer of carbon, and its structure is shown in Figure 1. The graphene size with $14 \times 14 \mathrm{Li}^{+}$occupied sites was used in the KMC simulations, using periodic boundary conditions for the simulation cell. Using the simulation size with $14 \times 14 \mathrm{Li}^{+}$occupied sites, good calculated results can be obtained, because it has been tested that the simulated results from the sizes of $21 \times 21$ and $28 \times 28 \mathrm{Li}^{+}$occupied sites are almost the same as those from the sizes of $14 \times 14$. The simulation temperature range is set to $230-330 \mathrm{~K}$. For all simulations, $5000 \mathrm{MC}$ steps are used, and the first $2000 \mathrm{MC}$ steps are disregarded. Thus, the system is allowed to relax to the equilibrium state. After it reaches equilibrium, the average value of the last $3000 \mathrm{MC}$ steps is the diffusion coefficient. For $\mathrm{Li}^{+}$-adsorbed graphene systems, $\mathrm{Li}^{+}$concentration range considered to be from 0.01 to 0.33 monolayer (ML) in KMC simulations. The interactions between Li ions were considered in estimation of macroscopic diffusion coefficient of Li ions. Since the interaction between Li ions decreases with the increase of distance, in this paper, to simplify calculations, we only considered the nearest, second-nearest and third-neighbor interactions. For single- $\mathrm{Li}^{+}$and two- $\mathrm{Li}^{+}$adsorbed graphene systems (here, two- $\mathrm{Li}^{+}$means that system contains one $\mathrm{Li}$ ion plus another $\mathrm{Li}$ ion), its migration energy barrier was directly obtained from total energy calculation of the systems using first-principle calculations. For $\mathrm{Li}$ ion with more than two Li neighbor ions, their migration energy barriers were derived from the results of the single- $\mathrm{Li}^{+}$and two- $\mathrm{Li}^{+}$adsorbed graphene systems according to an equation. The detailed introduction can be found below.
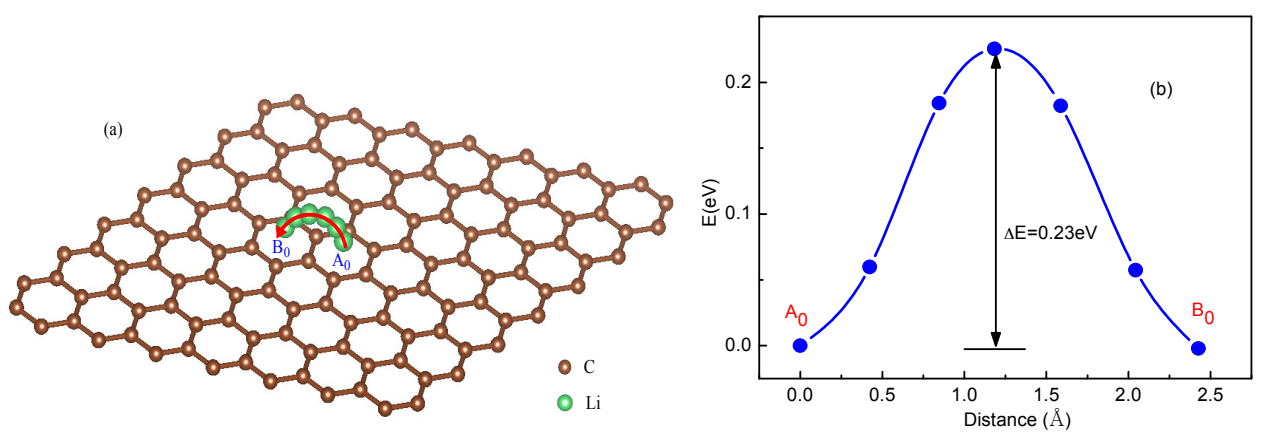

Figure 1. Schematic representation and total energy curve of a single Li ion diffusion on graphene following $A_{0}-B_{0}$ path.

\section{Results of DFT and KMC Calculations}

\subsection{Migration Energy Barrier in Single-Li $i^{+}$and Two-Li+ Adsorbed Graphene Systems}

Generally, there are three high symmetry sites considered for lithium ion adsorption on the graphene: top, hollow and bridge sites. The top site denotes the points up a carbon atom, and the hollow site denotes the center of a hexagon. Moreover, bridge site means the point up the midpoint of a carbon-carbon bond. The stability of a $\mathrm{Li}^{+}$-adsorbed graphene system is generally described by the following adsorption energy $E_{\mathrm{ad}}$ : [35]

$$
E_{\mathrm{ad}}=\left(E_{\mathrm{ad}+\mathrm{Gr}}-E_{\mathrm{ad}}-E_{\mathrm{Gr}}\right),
$$

where $E_{\mathrm{ad}+\mathrm{Gr}}$ denotes the total energy for $\mathrm{Li}^{+}$-adsorbed graphene system with a $\mathrm{Li}$ ion adsorbed on the graphene. $E_{\mathrm{ad}}$ and $E_{\mathrm{Gr}}$ are the energies of an isolated $\mathrm{Li}$ ion and the isolated graphene, respectively. The calculated adsorption energies $(-3.147 \mathrm{eV},-2.902 \mathrm{eV}$ and $-2.922 \mathrm{eV}$ for hollow, top and bridge sites, respectively) show that the most stable site locates the hollow one for the Li ion to be adsorbed on, which is consistent with previous research results [35]. Fan et al. found that for the single-layer graphene with the $\mathrm{Li} / \mathrm{C}$ ratio being less than $1 / 6, \mathrm{Li}$ was more likely to adsorb on the hollow site, and too high Li concentration would lead to more complex adsorption, such as no adsorption on the hollow site and a double adsorption [35]. Therefore, in this paper, only 
the $\mathrm{Li}^{+}$-adsorbed graphene systems with $\mathrm{Li}^{+} / \mathrm{C}$ ratio less than $1 / 6$ were studied. Moreover, in the following study of $\mathrm{Li}^{+}$diffusion on graphene by $\mathrm{KMC}$ simulations, $\mathrm{Li}$ ions migrated between hollow sites for all $\mathrm{Li}^{+}$-adsorbed graphene systems.

The diffusion energy barrier for Li ions can be obtained from the total energy curves of the $\mathrm{Li}^{+}$-adsorbed graphene systems along the diffusion pathway $[35,48]$. For a system with a single $\mathrm{Li}^{+}$, considering that $\mathrm{Li}^{+}$is able to migrate via jumping between neighboring hollow sites, the total energy curve along $A_{0}-B_{0}$ diffusion pathway was shown in Figure 1 . From the energy curve in Figure $1 \mathrm{~b}, \mathrm{a} \mathrm{Li}$ ion diffuses by overcoming an energy barrier $\Delta E=0.23 \mathrm{eV}$, which is near that of $0.311 \mathrm{eV}$ in Ref. [35], corresponding to an energy maximum point locating in the middle of diffusion pathway.

For rare $\mathrm{Li}$ ions adsorbed on graphene, $\mathrm{Li}^{+}$diffusion can be seen as the migration behavior for non-interacting particles. However, with the increase of $\mathrm{Li}^{+}$concentration, the interaction between $\mathrm{Li}$ ions will in fact appear inevitably in the experiment. Then, considering interaction between $\mathrm{Li}$ ions becomes important. To study the interaction between $\mathrm{Li}$ ions, we calculated total energies for the two- $\mathrm{Li}^{+}$adsorbed graphene systems that $\mathrm{Li}_{1}$ ion is fixed while $\mathrm{Li}_{2}$ ion is migrating, as shown in Figure 2. To simplify, we just considered the interactions between the nearest, second-nearest and third-neighbor Li ions. In Figure 2a, there are three possible migration pathways (labeled as $\left.\mathrm{B}_{1} \rightarrow \mathrm{A}_{1}, \mathrm{~B}_{1} \rightarrow \mathrm{D}_{1}, \mathrm{~B}_{1} \rightarrow \mathrm{C}_{1}\right)$ for $\mathrm{Li}_{2}$ ion in its migration behavior, when another $\mathrm{Li}_{1}$ ion has already existed on $\mathrm{Li}^{+}{ }_{2}$ 's nearest-neighbor site. $\mathrm{A}_{1}, \mathrm{D}_{1}$ and $\mathrm{C}_{1}$ sites correspond to the nearest, second-nearest and third-neighbor sites of $\mathrm{Li}_{1}$ ion, respectively. According to the total energy curve shown in Figure $2 b$, it is clearly found that $\mathrm{D}_{1}$ and $\mathrm{C}_{1}$ sites are more energetically favorable than $\mathrm{A}_{1}$ site in $\mathrm{Li}^{+}{ }_{2}$ 's migration behavior. $\mathrm{Li}^{+}{ }_{2}$ jumping from $\mathrm{B}_{1}$ to $\mathrm{C}_{1}$ site along migration pathway $\mathrm{B}_{1} \rightarrow \mathrm{C}_{1}$ needs to get over an energy barrier of about $0.63 \mathrm{eV}$. However, for the other two migration pathways $\mathrm{B}_{1} \rightarrow \mathrm{D}_{1}$ and $\mathrm{B}_{1} \rightarrow \mathrm{A}_{1}, \mathrm{Li}^{+}{ }_{2}$ can spontaneously jump from $B_{1}$ to $D_{1}\left(A_{1}\right)$ sites without overcoming the energy barrier. However, for $\mathrm{Li}^{+}{ }_{2}$ 's reverse migration processes from $\mathrm{D}_{1}, \mathrm{C}_{1}$ and $\mathrm{A}_{1}$ sites to $\mathrm{B}_{1}$ site, no matter which of the three pathways, all $\mathrm{Li}^{+}{ }_{2}$ needs to get over the high barriers of $0.63,0.69$ and $0.77 \mathrm{eV}$ for paths $\mathrm{C}_{1} \rightarrow \mathrm{B}_{1}$, $\mathrm{D}_{1} \rightarrow \mathrm{B}_{1}$ and $\mathrm{A}_{1} \rightarrow \mathrm{B}_{1}$, respectively. Figure $2 \mathrm{c}$ shows the total energy curve for $\mathrm{Li}^{+}{ }_{2}$ jumping between the second-nearest and third-neighbor sites of $\mathrm{Li}^{+}{ }_{1}\left(\mathrm{D}_{1}\right.$ and $\left.\mathrm{A}_{1}\right) \cdot \mathrm{Li}^{+}{ }_{2}$ needs to get over an energy barrier about $0.17 \mathrm{eV}$ when it jumps from $\mathrm{D}_{1}$ to $\mathrm{A}_{1}$. However, to jump from $\mathrm{A}_{1}$ to $\mathrm{D}_{1}$, it will get over a larger barrier of $0.26 \mathrm{eV}$, which is larger than that for a single $\mathrm{Li}^{+}$diffusion on graphene $(0.23 \mathrm{eV})$. Compared with the migration behavior for a single $\mathrm{Li}^{+}$'s diffusion on graphene, the migration behavior for the system with two Li ions becomes more complex. Obviously, these complex migration behaviors are as a result of the influences of $\mathrm{Li}^{+}{ }_{1}$ located nearby. Furthermore, the differences among migration behaviors for $\mathrm{Li}^{+}{ }_{2}$ along paths $\mathrm{B}_{1} \leftrightarrow \mathrm{D}_{1}, \mathrm{~B}_{1} \leftrightarrow \mathrm{C}_{1}, \mathrm{~B}_{1} \leftrightarrow \mathrm{A}_{1}$ and $\mathrm{A}_{1} \leftrightarrow \mathrm{D}_{1}$, as shown in Figure $2 \mathrm{~b}, \mathrm{c}$, further prove that interaction between close $\mathrm{Li}$ ions will greatly influence the migration direction and energy barrier. Moreover, it indicates that the interaction between Li ions should be considerable, especially for the system with high $\mathrm{Li}^{+}$concentration. The calculated results are similar to those in Refs. [51-56]. Takachi et al. found that $\mathrm{Li}-\mathrm{Li}$ or $\mathrm{Na}-\mathrm{Na}$ interaction resulted in the changing of the $\mathrm{Li}(\mathrm{Na})-$ graphene interaction, which gave rise to the enhancing energy barrier. Moreover, it was concluded that ideal single layer graphene is unsuitable to be used as an anode for Li-ion batteries [53].

For a multi- $\mathrm{Li}^{+}$adsorbed graphene system with high $\mathrm{Li}^{+}$concentration, $\mathrm{Li}$ ions would interact with each other through Coulomb repulsion. Such interactions of mutual Coulomb repulsion among many $\mathrm{Li}$ ions may play an important role on $\mathrm{Li}^{+ \text {'s }}$ migration energy barriers, consequently affecting their diffusion process on graphene. However, once the interactions among many ions are taken into account, the problem becomes very complicated. It is difficult to describe the interaction between $\mathrm{Li}$ ions on the energy barrier using first-principle calculations, because of $\mathrm{Li}^{+}$'s random nature of local bonding configurations. $\mathrm{Li}^{+\prime} \mathrm{s}$ arrangement changes at any time in diffusion process, so the corresponding $\mathrm{Li}^{+}$migration barriers subsequently vary. To provide a fundamental understanding of the influence of $\mathrm{Li}^{+\prime}$ s concentration on diffusion coefficient, we developed an equation to describe $\mathrm{Li}^{+}$migration energy barriers for multi- $\mathrm{Li}^{+}$adsorbed graphene system having $\mathrm{Li}^{+\prime} \mathrm{s}$ interactions in the following sections. It is well known that Coulomb interaction energy between two ions is inversely 
proportional to their distance. As the distance increases enough, the Coulomb interaction strength diminishes step by step. To simplify, here, we only consider the interactions between the nearest, second-nearest and third-neighbor $\mathrm{Li}$ ions to study the effects of $\mathrm{Li}^{+}$concentration on $\mathrm{Li}^{+}$diffusion coefficient for $\mathrm{Li}^{+}$-adsorbed graphene systems.
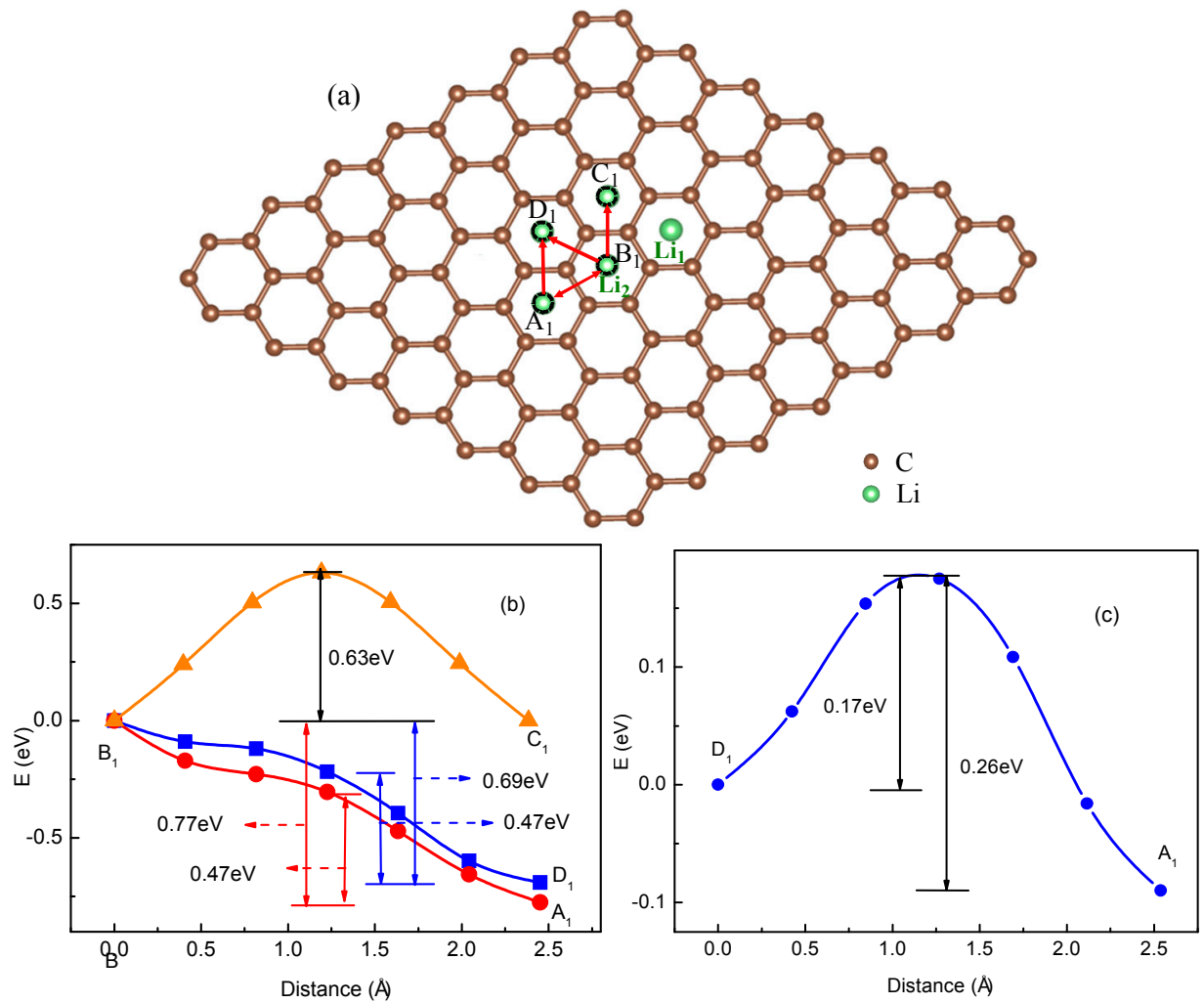

Figure 2. Schematic representations (a) and total energy curves for the system with two Li ions on graphene along (b) paths $\mathrm{B}_{1}-\mathrm{C}_{1}, \mathrm{~B}_{1}-\mathrm{A}_{1}$ and $\mathrm{B}_{1}-\mathrm{D}_{1}$; (c) path $\mathrm{D}_{1}-\mathrm{A}_{1} \cdot \mathrm{Li}^{+}{ }_{1}$ is migrating with $\mathrm{Li}^{+}{ }_{2}$ fixed.

\subsection{Method for Energy Barrier Estimation}

For multi- $\mathrm{Li}^{+}$adsorbed graphene system, as shown in Figure 3a, the energy for transition states on migration path can be estimated as

$$
\begin{aligned}
& E_{\mathrm{a}}=K_{1}\left(\frac{1}{\mathrm{r}_{0,1}}+\frac{1}{\mathrm{r}_{0,2}}+\frac{1}{\mathrm{r}_{0,3}}+\ldots+\frac{1}{\mathrm{r}_{0, \mathrm{i}}}\right)+K_{2} E_{0, \mathrm{gr}}+H_{\text {background }} \\
& E_{\mathrm{c}}=K_{1}\left(\frac{1}{\mathrm{r}_{0,1}^{\prime}}+\frac{1}{\mathrm{r}_{0,2}^{\prime}}+\frac{1}{\mathrm{r}_{0,3}^{\prime}}+\ldots+\frac{1}{\mathrm{r}_{0, \mathrm{i}}^{\prime}}\right)+K_{2} E_{0, \mathrm{gr}}^{\prime}+H_{\text {background }}
\end{aligned}
$$

where $E_{\mathrm{a}}$ and $E_{\mathrm{c}}$ denote the total energies for multi- $\mathrm{Li}^{+}$adsorbed graphene system with migrated Li ion (labeled as the 0 -th $\mathrm{Li}^{+}$) located on $a$ and $c$ sites of migration path, respectively. $E_{0, \mathrm{gr}}$ and $E_{0, \mathrm{gr}}^{\prime}$ are the energies for the systems which are only composed of graphene and the $0-\mathrm{th} \mathrm{Li}^{+}$located on $a$ and $c$ sites, respectively. $H_{\text {background }}$ denotes the total energy for multi- $\mathrm{Li}^{+}$adsorbed graphene system in which the 0 -th $\mathrm{Li}$ ion is removed. $K_{1}$ and $K_{2}$ are proportionality coefficients. $r_{0, \mathrm{i}}$ and $r_{0, \mathrm{i}}^{\prime}$ are the distances between the 0 -th and $i$-th $\mathrm{Li}$ ion.

Combining Equation (5) with Equation (6), the energy difference $\Delta E_{\mathrm{ac}}$ for two transition states on the migration path can be evaluated as

$$
\Delta E_{\mathrm{ac}}=E_{\mathrm{a}}-E_{\mathrm{c}}=K_{1}\left[\left(\frac{1}{\mathrm{r}_{0,1}}-\frac{1}{\mathrm{r}_{0,1}^{\prime}}\right)+\left(\frac{1}{\mathrm{r}_{0,2}}-\frac{1}{\mathrm{r}_{0,2}^{\prime}}\right)+\ldots+\left(\frac{1}{\mathrm{r}_{0, \mathrm{i}}}-\frac{1}{\mathrm{r}_{0, \mathrm{i}}^{\prime}}\right)\right]+K_{2}\left(E_{0, \mathrm{gr}}-E_{0, \mathrm{gr}}^{\prime}\right) .
$$


For a two- $\mathrm{Li}^{+}$adsorbed graphene system, such as the system in which only two Li ions ( 0 -th and 1-th Li ions) are adsorbed on the graphene, the energy for transition states on migration path can be estimated as

$$
\begin{aligned}
& E_{0,1}=K_{1} \frac{1}{\mathrm{r}_{0,1}}+K_{2} \mathrm{E}_{0, \mathrm{gr}}+E_{\text {background }} \\
& E_{0,1}^{\prime}=K_{1} \frac{1}{\mathrm{r}_{0,1}^{\prime}}+K_{2} \mathrm{E}_{0, \mathrm{gr}}^{\prime}+E_{\text {background }} .
\end{aligned}
$$

where $E_{0,1}$ and $E_{0,1}^{\prime}$ are the energies of two- $\mathrm{Li}^{+}$adsorbed graphene system with the 0 -th Li ion located on $a$ and $c$ sites on migration path, respectively. $E_{\text {background }}$ is the energy of the two- $\mathrm{Li}^{+}$adsorbed graphene system in which the 0 -th $\mathrm{Li}$ ion is removed.

Combining Equation (8) with Equation (9), the energy difference $\Delta E_{0,1}$ for two transition states on the migration path can be evaluated as

$$
\Delta E_{0,1}=E_{0,1}-E_{0,1}^{\prime}=K_{1}\left(\frac{1}{\mathrm{r}_{0,1}}-\frac{1}{\mathrm{r}_{0,1}^{\prime}}\right)+K_{2}\left(E_{0, \mathrm{gr}}-E_{0, \mathrm{gr}}^{\prime}\right) .
$$

Analogously, for the two- $\mathrm{Li}^{+}$adsorbed graphene systems which are only composed of the 2-nd or 3-rd or $i$-th $\mathrm{Li}$ ion and the 0 -th $\mathrm{Li}$ ion and graphene, the energy differences $\Delta \mathrm{E}_{0,2} \ldots$ and $\Delta \mathrm{E}_{0, \mathrm{i}}$ for the 0 -th Li ion jumping from $a$ site into $c$ site are written as:

$$
\begin{gathered}
\Delta E_{0,2}=E_{0,2}-E_{0,2}^{\prime}=K_{1}\left(\frac{1}{\mathrm{r}_{0,2}}-\frac{1}{\mathrm{r}_{0,2}^{\prime}}\right)+K_{2}\left(E_{0, \mathrm{gr}}-E_{0, \mathrm{gr}}^{\prime}\right), \\
\cdots \\
\Delta E_{0, \mathrm{i}}=E_{0, \mathrm{i}}-E_{0, \mathrm{i}}^{\prime}=K_{1}\left(\frac{1}{\mathrm{r}_{0, \mathrm{i}}}-\frac{1}{\mathrm{r}_{0, \mathrm{i}}^{\prime}}\right)+K_{2}\left(E_{0, \mathrm{gr}}-E_{0, \mathrm{gr}}^{\prime}\right) .
\end{gathered}
$$

Thus, combining Equation (7) with Equations (10)-(12), the energy difference for a multi- $\mathrm{Li}^{+}$ adsorbed graphene system can be derived as

$$
\Delta E_{\mathrm{ac}}=\left(\Delta E_{0,1}+\Delta E_{0,2}+\ldots+\Delta E_{0, \mathrm{i}}\right)-(\mathrm{i}-1) \times \Delta E_{0, \mathrm{gr}}
$$

where, $\Delta E_{0, \mathrm{gr}}=K_{2}\left(E_{0, \mathrm{gr}}-E_{0, \mathrm{gr}}^{\prime}\right)$ is the energy difference for one- $\mathrm{Li}^{+}$adsorbed graphene system with single $\mathrm{Li}^{+}$migrating from $a$ site into $c$ site. Moreover, it was estimated to be about $0.23 \mathrm{eV}$, as shown in Figure 1. In Equation (13), the first term is the energy differences corresponding to two transition states on migration path for those two- $\mathrm{Li}^{+}$adsorbed graphene systems. The second term is only related to the single- $\mathrm{Li}^{+}$adsorbed graphene system with no interaction between Li ions. If two transition states correspond respectively to the activated state and initial state of the ionic hoping, the energy difference is the diffusion barriers. Thus, we can simply estimate the diffusion barriers for multi- $\mathrm{Li}^{+}$adsorbed graphene systems from diffusion barriers of two- $\mathrm{Li}^{+}$and single- $\mathrm{Li}^{+}$adsorbed graphene systems shown in Figures $2 b$ and $1 b$ according to Equation (13). Similarly, as the distance between two ions increases, the Coulomb interaction energy between them decreases. This can be also proved from Figure 1b, Figure $2 b, c$. When $\mathrm{Li}^{+}{ }_{2}$ jumps between the second-nearest and third-neighbor sites of $\mathrm{Li}^{+}{ }_{1}\left(\mathrm{D}_{1}\right.$ and $\mathrm{A}_{1}$ ), the energy barriers are about 0.17 and $0.26 \mathrm{eV}$, which is close to that for a single $\mathrm{Li}^{+}$diffusion on graphene $(0.23 \mathrm{eV})$. Compared with that for $\mathrm{B}_{1} \leftrightarrow \mathrm{D}_{1}, \mathrm{~B}_{1} \leftrightarrow \mathrm{C}_{1}$ and $\mathrm{B}_{1} \leftrightarrow \mathrm{A}_{1}$ paths, the interaction between $\mathrm{Li}^{+}{ }_{1}$ and $\mathrm{Li}^{+}{ }_{2}$ evidently weakens a lot. Therefore, to simplify, it is reasonable to only consider the interactions between the nearest, second-nearest and third-neighbor Li ions in the study of the diffusion barriers for multi- $\mathrm{Li}^{+}$adsorbed graphene systems. 

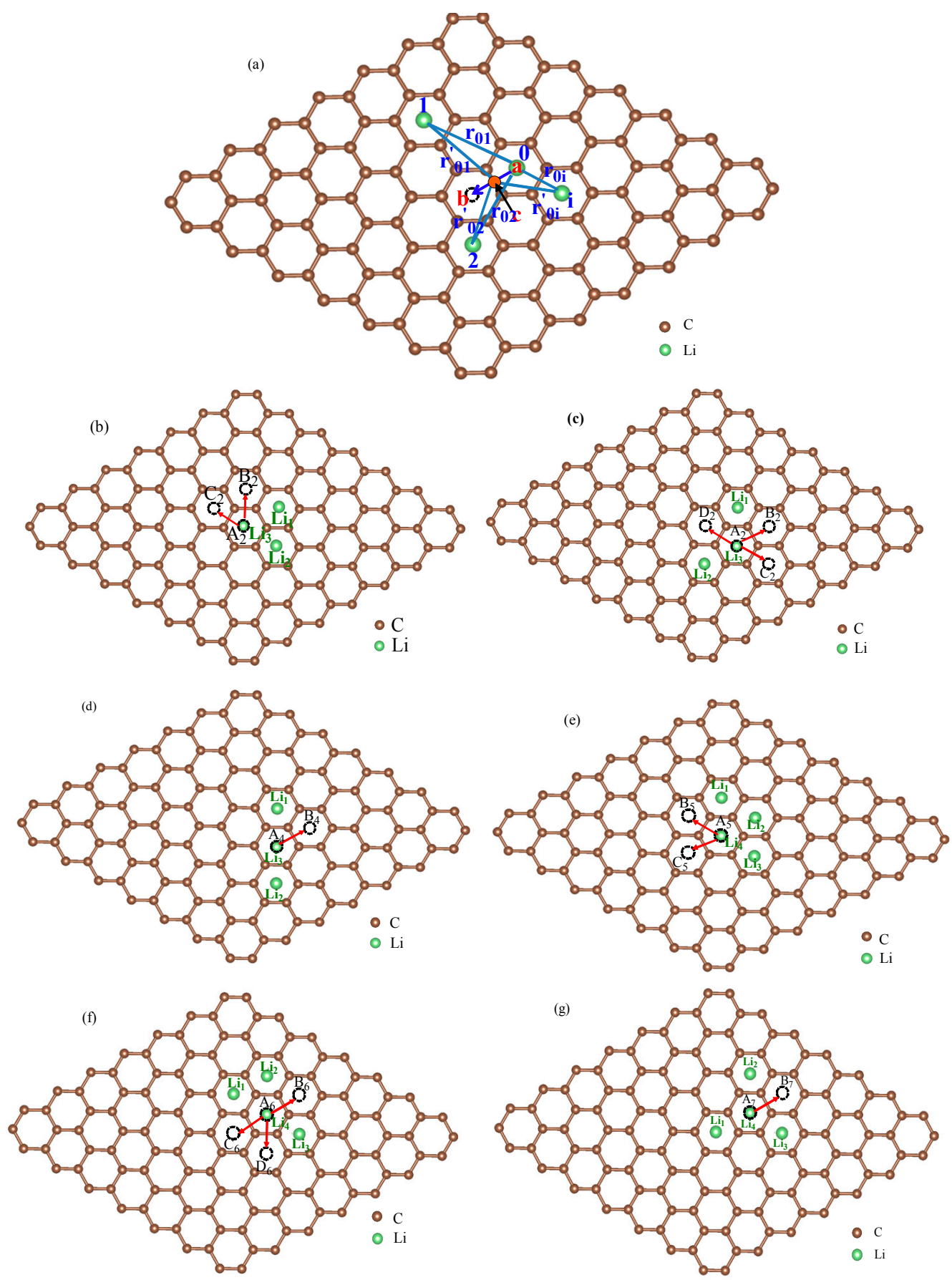

Figure 3. The schematic view of multi- $\mathrm{Li}^{+}$adsorbed graphene system (a) and schematic representations for various possible $\mathrm{Li}^{+}$arrangements and $\mathrm{Li}^{+}$s possible migration pathways for three- $\mathrm{Li}^{+}$and four- $\mathrm{Li}^{+}$ adsorbed systems with one $\mathrm{Li}^{+}$migrating on graphene and the others fixed $(\mathbf{b}-\mathbf{g})$.

To verify the method for energy barrier estimation, we presented that energy barriers can be estimated by combining Equation (13) and total energy curves obtained from first-principle calculations along various possible migration pathways for three- $\mathrm{Li}^{+}$and four- $\mathrm{Li}^{+}$adsorbed graphene systems These systems have various possible $\mathrm{Li}^{+}$arrangements. Because the $\mathrm{Li}^{+}$-adsorbed graphene systems considered in this paper only involve those with low $\mathrm{Li}^{+}$concentration, as mentioned previously, $\mathrm{Li}^{+}$ basically has no more than three neighbors. This can also be confirmed in later sections. Therefore, total energy calculations are only performed on three- $\mathrm{Li}^{+}$and four- $\mathrm{Li}^{+}$adsorbed graphene systems. Figure $3 \mathrm{~b}-\mathrm{g}$ shows the systems with various possible $\mathrm{Li}^{+}$arrangements and $\mathrm{Li}^{+}$'s various possible 
migration pathways, respectively. The migration pathways are labeled as P1-P24 in Figure 4a-f. For example, the migration pathway labeled as $\mathrm{P} 1$ denotes that $\mathrm{Li}^{+}$migrates from $\mathrm{A}_{2}$ site to $\mathrm{B}_{2}$ site shown in Figure $3 b$, and $\mathrm{P} 2$ denotes $\mathrm{Li}^{+}$migrates from $\mathrm{B}_{2}$ site to $\mathrm{A}_{2}$ site. Figure $4 a-f$ shows the total energy curves along migration pathways corresponding to Figure $3 b-g$. Directly from the total energy curves, $\mathrm{Li}^{+}$diffusion barriers are easily obtained, which are displayed in Figure $4 \mathrm{a}-\mathrm{f}$. From Figure $4 \mathrm{a}-\mathrm{f}$, it is indicated once again that the interaction between ions affects $\mathrm{Li}^{+\prime} \mathrm{s}$ migtation behavior greatly. As a result, the migrated Li ion energetically prefers to jump into the site far away from the other Li ions. Through another method, the diffusion energy barriers corresponding to Figure $3 \mathrm{~b}-\mathrm{g}$ can be also calculated by Equation (13) based on the total energy curves of single- $\mathrm{Li}^{+}$and two- $\mathrm{Li}^{+}$ adsorbed graphene systems obtained from first-principles calculations, as found in Figures $1 b$ and $2 b$. Comparison of all diffusion barriers obtained by the two above methods for various $\mathrm{Li}^{+}$s migration paths P1-P24 is shown in Figure 5. From the figure, it can be observed that the calculated results from both methods are consistent. The mean deviation $\Delta$ can be calculated as follows:

$$
\Delta=\frac{1}{N} \sum_{\mathrm{i}=1}^{N} \frac{\left|D_{\mathrm{i}, \mathrm{ab}}-D_{\mathrm{i}, \mathrm{eq}}\right|}{D_{\mathrm{i}, \mathrm{eq}}} \times 100 \%
$$

$N$ denotes the number of the samples. $D_{\mathrm{i}, \mathrm{ab}}$ and $D_{\mathrm{i}, \mathrm{eq}}$ result from first-principles calculations and Equation (13), respectively. The mean deviation $\Delta$ is calculated to be $9.97 \%$. Therefore, the method that combining Equation (13) with the total energy curves of single- $\mathrm{Li}^{+}$and two- $\mathrm{Li}^{+}$adsorbed graphene systems from first-principles calculations, works well in estimating the diffusion barriers for multi- $\mathrm{Li}^{+}$ adsorbed graphene systems having $\mathrm{Li}^{+}$'s interaction. Using the diffusion barriers obtained from Equation (13), we can apply KMC to predict the macroscopic $\mathrm{Li}^{+}$diffusion coefficient.
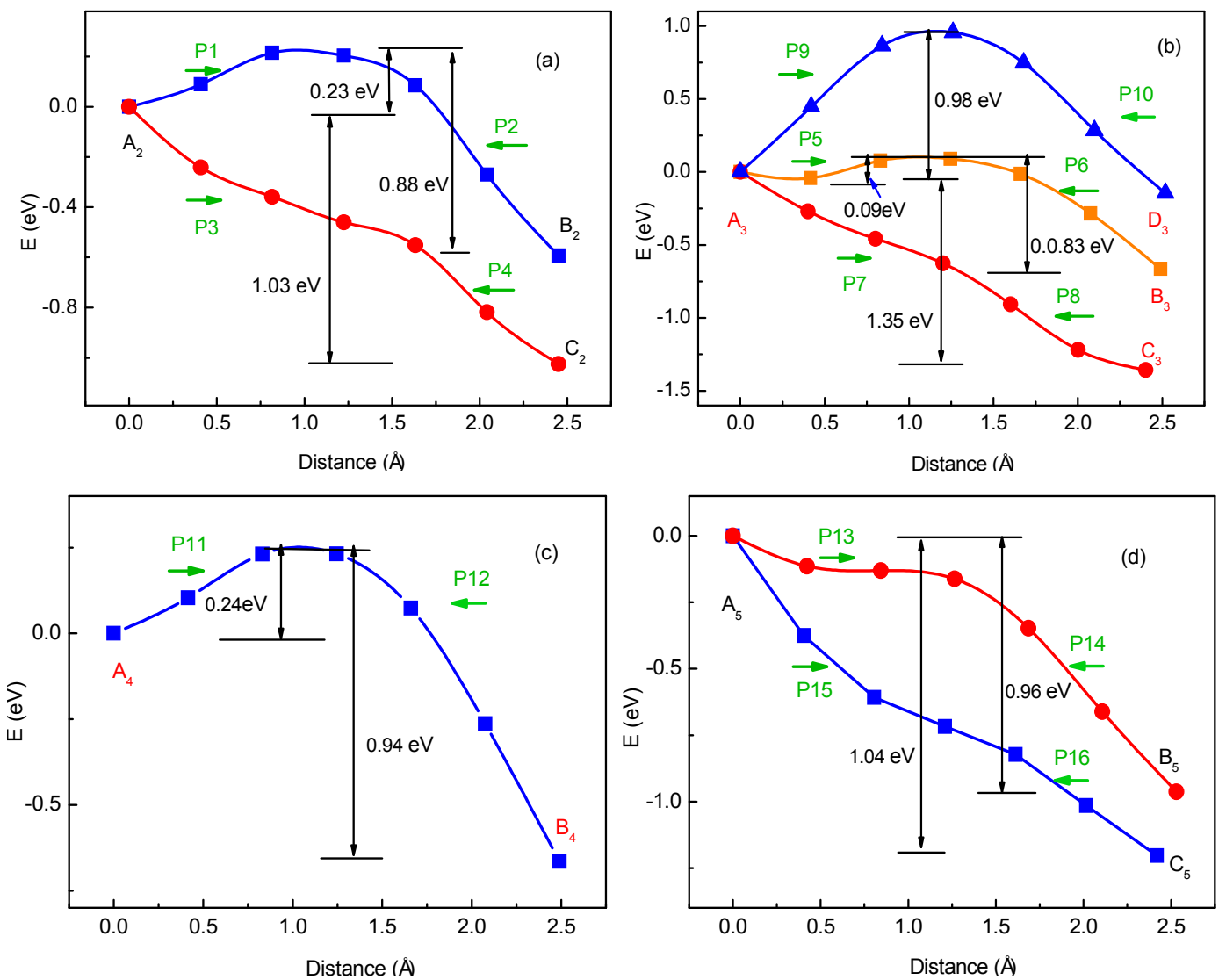

Figure 4. Cont. 

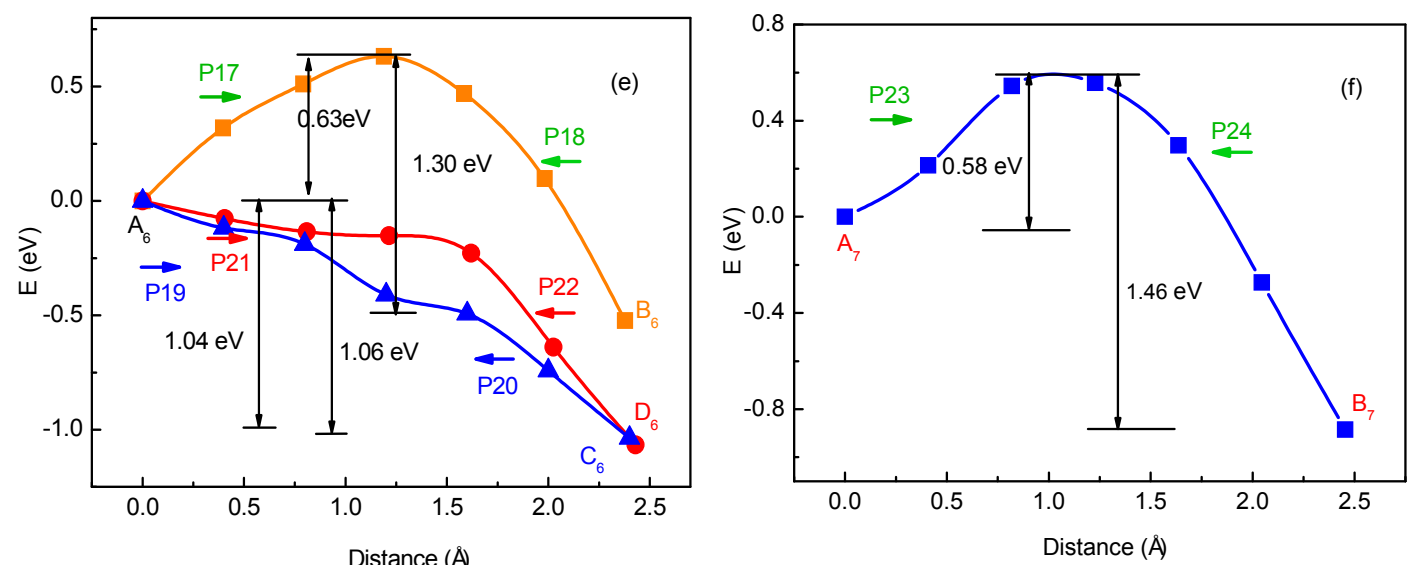

Figure 4. Total energy curves along $\mathrm{Li}^{+}$'s migration pathways labeled as $\mathrm{P} 1-\mathrm{P} 24$ for three- $\mathrm{Li}^{+}$and four- $\mathrm{Li}^{+}$adsorbed systems with $\mathrm{Li}^{+}$arrangements shown in Figure $3 \mathrm{~b}-\mathrm{g}$.

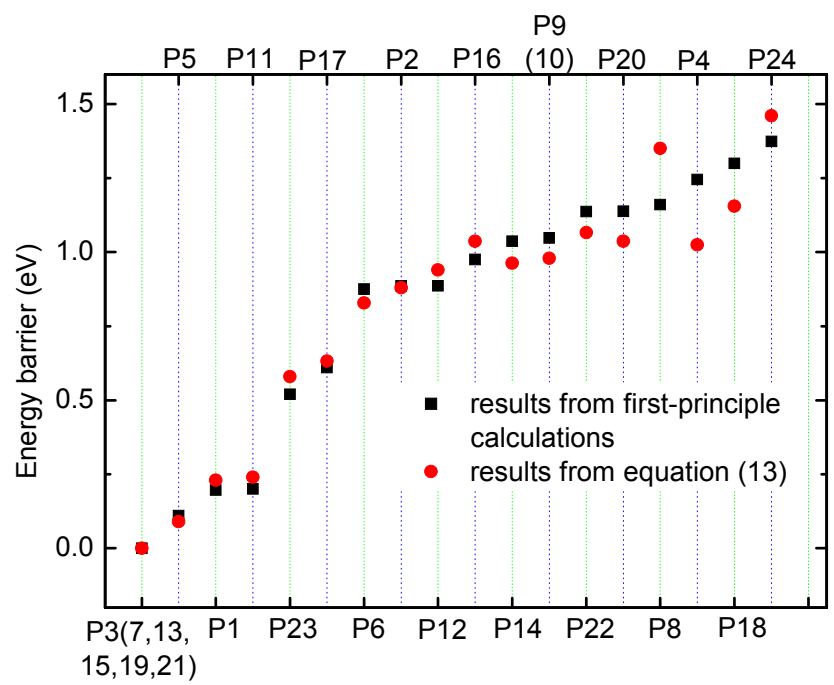

Figure 5. The energy barriers obtained from first-principle calculations and from Equation (13) for various $\mathrm{Li}^{+\prime}$ s migration paths P1-P24 shown in Figure 4a-f.

Our calculated $\mathrm{Li}^{+}$diffusion coefficients for the systems with rare $\mathrm{Li}^{+}$adsorption (such as the system with $\mathrm{Li}^{+} / \mathrm{C}$ rate of 0.045 ) at room temperature are the value $D_{\mathrm{Li}} \sim 10^{-7} \mathrm{~cm}^{2} \cdot \mathrm{s}^{-1}$. It agrees well with the result of previous theoretical and experimental research of intra-layer $\mathrm{Li}^{+}$diffusion in graphite [57]. Moreover, it confirms that our KMC simulations are reliable.

\subsection{Concentration Effects on $\mathrm{Li}^{+}$Diffusion Coefficient}

The diffusion coefficient is an important parameter to determine the diffusion velocity of $\mathrm{Li}^{+}$, because it presents a more quantitative description of the diffusion features. In the experimental studies of electrochemical impedance spectroscopy (EIS), from the data analysis in the low-frequency region, the $\mathrm{Li}^{+}$diffusion coefficient was estimated according to the following Equations [20-22]:

$$
D_{\mathrm{Li}}=\frac{R^{2} T^{2}}{2 A^{2} n^{4} F^{4} \sigma^{2} C_{\mathrm{Li}}^{2}}
$$

and

$$
\mathrm{Z}_{\omega}=R_{\mathrm{ct}}+R_{1}+\sigma \omega^{-1 / 2}
$$


where, $D_{\mathrm{Li}}$ is $\mathrm{Li}^{+}$diffusion coefficient, $C_{\mathrm{Li}}$ is the concentration of $\mathrm{Li}$ ion, $T$ denotes the absolute temperature, $R$ is the gas constant, $A$ means the surface area, $n$ denotes the number of electrons per molecule during oxidization, $\sigma$ is the Warburg factor, and $F$ is the Faraday's constant, $Z_{\omega}$ is the Warburg impedance, and $\omega$ is frequency.

For the same temperature, we introduce a new parameter $Q_{1}$,

$$
Q_{1}=\frac{R^{2} T^{2}}{2 A^{2} n^{4} F^{4} \sigma^{2}}
$$

then Equation (15) can be rewritten as follows:

$$
D_{\mathrm{Li}}=Q_{1} C_{\mathrm{Li}}^{-2}
$$

The logarithm on both sides of the Equation (18) can be changed into:

$$
\ln \left(D_{\mathrm{Li}}\right)=\ln Q_{1}-2 \ln \left(C_{\mathrm{Li}}\right) .
$$

To study the concentration effects on $\mathrm{Li}^{+}$diffusion coefficient, the KMC calculated method was used to calculate $\mathrm{Li}^{+}$diffusion coefficients for $\mathrm{Li}^{+}$-adsorbed graphene systems. Based on the previous research results [35] that too high $\mathrm{Li}^{+}$concentration would lead to more complex adsorption, our research systems were only restricted to those $\mathrm{Li}^{+}$-adsorbed graphene systems with $\mathrm{Li}^{+} / \mathrm{C}$ ratio of less than $1 / 6$ (equivalent to that $C_{\mathrm{Li}}$ is less than $0.337 \mathrm{ML}$ ).

The relationship between the calculated diffusion coefficient $D_{\mathrm{Li}}$ and $\mathrm{Li}^{+}$concentration $\mathrm{C}_{\mathrm{Li}}$ is shown in Figure 6a. From Figure 6a, it can be evidently seen that $D_{\mathrm{Li}}$ decreases quickly with increasing $\mathrm{Li}^{+}$concentration in very low concentration region for all temperatures, and decreases slowly in comparatively high Li concentration regions. Figure $6 \mathrm{~b}$ shows $\ln \left(D_{\mathrm{Li}}\right)$ as a function of $-\ln \left(C_{\mathrm{Li}}\right)$ at $T=233,273$ and $333 \mathrm{~K}$. Unfortunately, it is quite clear that the calculated results do not fully meet the expected results from Equation (19), which has usually been used to estimate diffusion coefficients in an experiment. To get a deep insight into the relationship between the diffusion coefficient and concentration, the curve of $\ln \left(D_{\mathrm{Li}}\right)$ as a function of $-\ln \left(C_{\mathrm{Li}}\right)$ was divided into two parts: low concentration region $\left(C_{\mathrm{Li}}\right.$ in range of $\left.0.01-0.11 \mathrm{ML}\right)$ shown in Figure $6 \mathrm{c}$ and relatively high concentration region $\left(C_{\mathrm{Li}}\right.$ in range of $0.21-0.33 \mathrm{ML}$ ) shown in Figure $6 \mathrm{~d}$. In Figure $6 \mathrm{c}, \mathrm{d}$, the solid lines are the corresponding fitting lines. The fitting line slopes denote that the indexes $\beta$ of $C_{\mathrm{Li}}$ are about equal to 1.44 and 7.95 for low and relatively high concentration regions at $T=273 \mathrm{~K}$, respectively. Although the cases for other temperatures are not listed, the change trend for all other temperatures is the same. The slope $\beta$ and correlation coefficients $r_{1}$ for the linear fitting line for all temperatures are listed in Table 1. As seen in Table 1, the values of $\beta$ in low concentration region $(0.01-0.11 \mathrm{ML})$ are almost the same as that in temperature region of $233-333 \mathrm{~K}$, which generally conforms to the law described by Equation (19). This indicates that in a low concentration region the relationship between $D_{\mathrm{Li}}$ and $C_{\mathrm{Li}}$ is roughly fitted to that of Equation (19). However, for a high concentration region $\left(C_{\mathrm{Li}}\right.$ in range of $0.21-0.33 \mathrm{ML}$ ), the slope $\beta$ gradually decreases from 8.94 at $T=233 \mathrm{~K}$ to 6.88 at $T=333 \mathrm{~K}$. The value of $\beta$ seriously deviates from 2 . Therefore, the calculated results imply that Equation (15) could not be simply used to estimate the $\mathrm{Li}^{+}$diffusion coefficient for all $\mathrm{Li}^{+}$-adsorbed graphene systems with various $\mathrm{Li}^{+}$ concentration, and it is only suitable for those systems with very low $\mathrm{Li}^{+}$concentration in which the interaction between $\mathrm{Li}$ ions is very small. The calculated results are consistent with the experimental facts $[23,53,58-61]$. Takachi et al. studied the concentration dependence of $\mathrm{Li}^{+} / \mathrm{Na}^{+}$diffusion in manganese hexacyanoferrates [53]. It is found that the potential barrier and diffusion coefficient of $\mathrm{Na}^{+}$ increases with increasing $\mathrm{Na}^{+}$content, while those of $\mathrm{Li}^{+}$decrease with increasing $\mathrm{Li}^{+}$content, which is because the number of $\mathrm{Li}^{+}$sites is three times that of the $\mathrm{Na}^{+}$sites. In the low $\mathrm{Li}^{+}$content, $\mathrm{Li}^{+}$diffusion appears in $\mathrm{Li}^{+}$diffusion path with a lower single-ion potential barrier. The experimental results indicate that the interaction between $\mathrm{Li}^{+} / \mathrm{Na}^{+}$will play important roles in the diffusion coefficient. Takami and Piao et al. measured the diffusion coefficients of carbon electrodes $[23,58]$. They found that 
the diffusion coefficient decreased with increasing $\mathrm{Li}^{+}$content. However, the changing slope of the diffusion coefficient is different for low and high intercalation $\mathrm{Li}^{+}$regions. Similar changing relations were also found in $\mathrm{Li}_{1-\mathrm{x}} \mathrm{Ni}_{0.33} \mathrm{Mn}_{0.33} \mathrm{Co}_{0.33} \mathrm{O}_{2}$ and $\mathrm{Li}_{1-\mathrm{x}} \mathrm{Ni}_{0.50} \mathrm{Mn}_{0.20} \mathrm{Co}_{0.30} \mathrm{O}_{2}[59,60]$. Chou et al. studied $\mathrm{Li}$ diffusion behavior in $\mathrm{a}-\mathrm{Li}_{\mathrm{x}} \mathrm{Si}$ and $\mathrm{a}-\mathrm{Li}_{\mathrm{x}} \mathrm{Ge}$ [61]. They found different $\mathrm{Li}^{+}$content dependence of the $\mathrm{Li}^{+}$diffusion coefficient. The $\mathrm{Li}^{+}$diffusion coefficient increases with increasing $\mathrm{Li}^{+}$content for $\mathrm{a}-\mathrm{Li}_{\mathrm{x}} \mathrm{Si}$, and decreases with increasing $\mathrm{Li}^{+}$content for a- $\mathrm{Li}_{\mathrm{x}} \mathrm{Ge}$. Therefore, interactions between $\mathrm{Li}$ ions, and among $\mathrm{Li}$ ion and host atoms will all influence the $\mathrm{Li}^{+}$diffusion, which determines that the $\mathrm{Li}^{+}$ intercalation content dependence of $\mathrm{Li}^{+}$diffusion coefficient should be changed and complex.
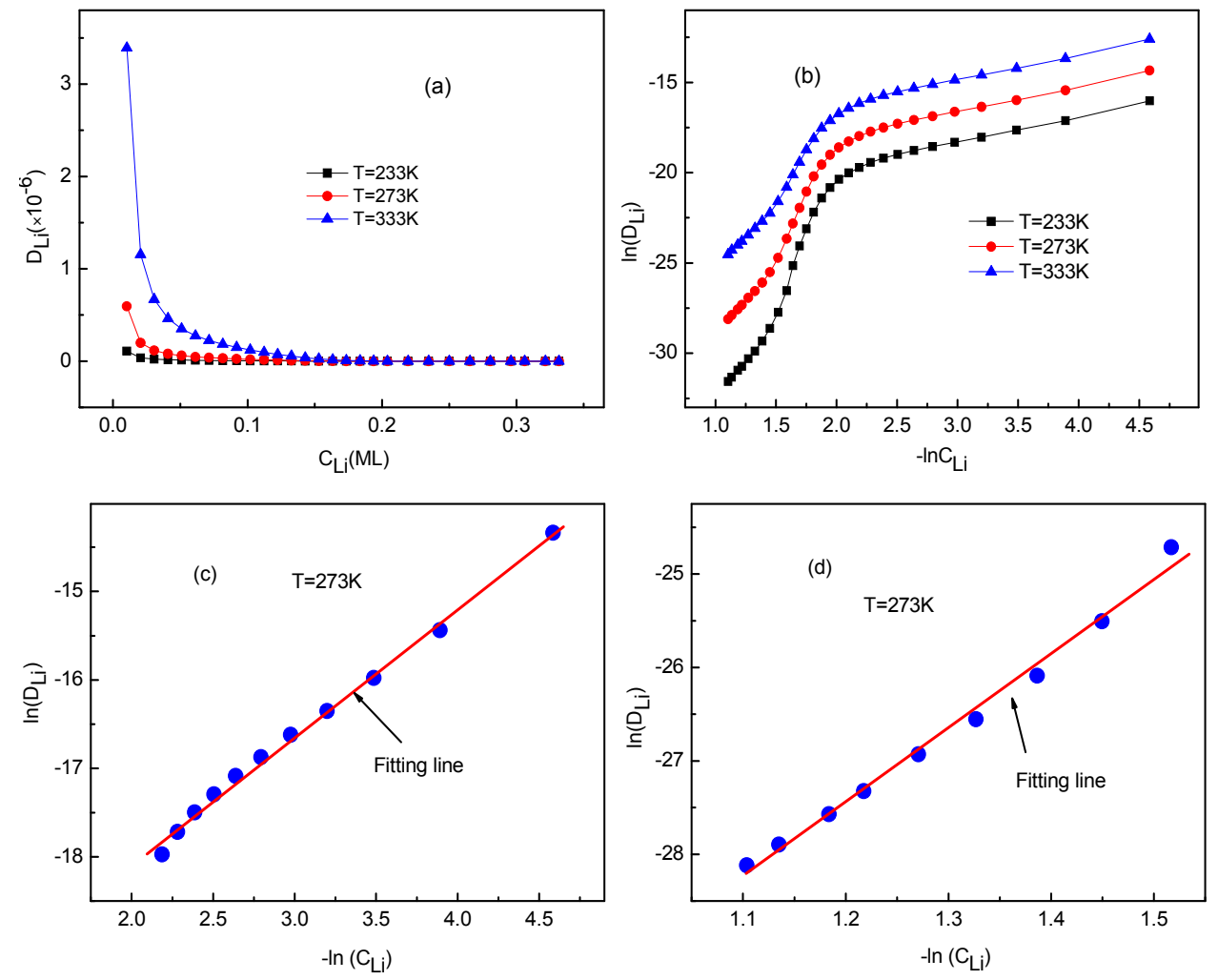

Figure 6. (a) The diffusion coefficient $D_{\mathrm{Li}}$ as a function of $\mathrm{Li}^{+}$concentration $C_{\mathrm{Li}}$; (b) the logarithm of $D_{\mathrm{Li}}$ as a function of the logarithm of $C_{\mathrm{Li}}$, at $T=233,273$ and $333 \mathrm{~K}$. The logarithm $\ln \left(D_{\mathrm{Li}}\right)$ as a function of $-\ln \left(C_{\mathrm{Li}}\right)$ for $C_{\mathrm{Li}}$ for (c) low concentration region, and (d) high concentration region at $T=273 \mathrm{~K}$. The solid lines are the fitting ones.

Table 1. The slope $\beta$ and correlation coefficient $r_{1}$ for the linear fitting line between $\ln \left(D_{\mathrm{Li}}\right)$ and $\ln \left(C_{\mathrm{Li}}\right)$ in different region of concentration $C_{\mathrm{Li}}(\mathrm{ML})$ at various temperatures.

\begin{tabular}{|c|c|c|c|c|c|c|c|}
\hline \multirow{2}{*}{$\begin{array}{l}\text { Concentration } \\
\mathrm{C}_{\mathrm{Li}}(\mathrm{ML})\end{array}$} & \multicolumn{7}{|c|}{ Temperature T (K) } \\
\hline & & $\mathrm{T}=233$ & $\mathrm{~T}=243$ & $T=253$ & $T=263$ & $T=273$ & $\mathrm{~T}=283$ \\
\hline \multirow{2}{*}{$0.01-0.11$} & $\beta$ & $1.46 \pm 0.04$ & $1.46 \pm 0.0$ & $1.45 \pm 0.04$ & $1.45 \pm 0.03$ & $1.44 \pm 0.03$ & $1.44 \pm 0.03$ \\
\hline & $r_{1}$ & 0.9936 & 0.9947 & 0.9942 & 0.9953 & 0.9949 & 0.9953 \\
\hline \multirow{3}{*}{$0.21-0.33$} & $\beta$ & $8.94 \pm 0.38$ & $8.69 \pm 0.35$ & $8.34 \pm 0.34$ & $8.04 \pm 0.30$ & $7.95 \pm 0.28$ & $7.80 \pm 0.25$ \\
\hline & $r_{1}$ & 0.9859 & 0.9871 & 0.9866 & 0.9892 & 0.9899 & 0.9916 \\
\hline & & $T=293$ & $\mathrm{~T}=303$ & $\mathrm{~T}=313$ & $\mathrm{~T}=323$ & $T=333$ & \\
\hline \multirow{2}{*}{$0.01-0.11$} & $\beta$ & $1.43 \pm 0.03$ & $1.43 \pm 0.03$ & $1.44 \pm 0.03$ & $1.43 \pm 0.03$ & $1.42 \pm 0.03$ & \\
\hline & $r_{1}$ & 0.9956 & 0.9963 & 0.9957 & 0.9960 & 0.9961 & \\
\hline \multirow{2}{*}{$0.16-0.33$} & $\beta$ & $7.58 \pm 0.28$ & $7.29 \pm 0.28$ & $7.16 \pm 0.21$ & $7.08 \pm 0.20$ & $6.88 \pm 0.16$ & \\
\hline & $r_{1}$ & 0.9886 & 0.9884 & 0.9915 & 0.99354 & 0.9954 & \\
\hline
\end{tabular}


The occupying rates of $\mathrm{Li}$ ion having $0,1,2$ or 3 neighbors can be calculated as well. The KMC simulated results indicate that these rates are unaffected by temperature. Moreover, the rates of $\mathrm{Li}$ having 4 or more neighbors are always zero for $\mathrm{Li}$ ion concentration $<0.33 \mathrm{ML}$. This coincides with the $\mathrm{Li}$ arrangements shown in Figure $3 \mathrm{~b}-\mathrm{g}$, which was considered in the deriving process of Equation (13). Figure 7 shows the occupying rates of $\mathrm{Li}^{+}$with $0-3$ neighbors for all systems at $T=273 \mathrm{~K}$ for different $\mathrm{Li}$ ion concentration. In fact, the distribution of $\mathrm{Li}$ ion is decentralized in the system with low $\mathrm{Li}^{+}$ concentration, so it has no neighbors in a certain range. This corresponds to the case shown in Figure 7. With the increase of $\mathrm{Li}$ ion concentration, more $\mathrm{Li}$ ions are located close to each other. As a result, some Li ions have neighbors and the occupying rates with 1-3 neighbors increase, as shown in Figure 7. The temperature effects on the $\mathrm{Li}^{+}$diffusion coefficient will be discussed in the next section.

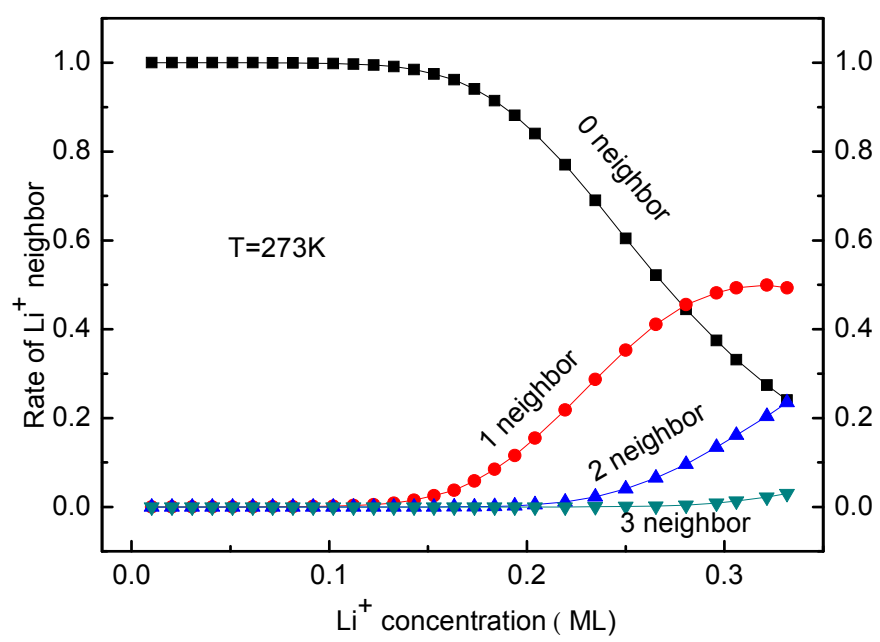

Figure 7. Rates of $\mathrm{Li}^{+}$with $0-3$ neighbors at $\mathrm{T}=273 \mathrm{~K}$ for different $\mathrm{Li}$ ion concentration.

\subsection{Temperature Effects on $\mathrm{Li}^{+}$Diffusion Coefficient}

Generally, according to the Arrhenius law the diffusion coefficient as a function of temperature is estimated as: $[62,63]$

$$
D_{\mathrm{Li}}(T)=D_{0} \exp \left(-\frac{E_{\mathrm{A}}}{k_{\mathrm{B}} T}\right) .
$$

$D_{0}$ is the pre-exponential factor, $E_{\mathrm{A}}$ is activation energy. It should be noted that the activation energy in the Arrhenius equation reflects macroscopic activation energy and differs from the energy barrier for TST formulas. Take the logarithm on both sides of the Equation (20), it can be changed into:

$$
\ln \left(D_{\mathrm{Li}}\right)=-\frac{E_{\mathrm{A}}}{k_{\mathrm{B}} T}+\ln \left(D_{0}\right) .
$$

In order to study the temperature effects on the $\mathrm{Li}^{+}$diffusion coefficient, we have calculated the diffusion coefficients for the $\mathrm{Li}^{+}$-adsorbed graphene systems in a temperature range of 233-333 K. The calculated $\mathrm{Li}^{+}$diffusion coefficient $D_{\mathrm{Li}}$ as a function of temperature is shown in Figure 8a. From the figure, it can be seen that $D_{\mathrm{Li}}$ increases with enhancing temperature for all $\mathrm{Li}^{+}$concentrations. Moreover, with increasing $\mathrm{Li}^{+}$concentration, the change of $D_{\mathrm{Li}}$ slows down quickly. Obviously, $D_{\mathrm{Li}}$ does not follow a quadratic relation shown in Equation (15). Additionally, the $\frac{1}{k_{\mathrm{B}} T}$ dependence of $\ln \left(D_{\mathrm{Li}}\right)$, and their fitting curves are presented in Figure $8 \mathrm{~b}$. It can obviously be observed that there is a linear relationship between $\ln \left(D_{\mathrm{Li}}\right)$ and $\frac{1}{k_{\mathrm{B}} T}$. This indicates that the obtained diffusion coefficients follow the Arrhenius equation, which is similar to other research results $[62,63]$ rather than meeting that from Equation (15). The slope $\alpha$ corresponds to the negative of the macroscopic migration energy barrier $\left(-E_{\mathrm{A}}\right)$. Furthermore, the slope $\alpha$ and correlation coefficient $r_{2}$ for the fitting curves are listed in Table 2. The negative of the slope value of $0.23 \mathrm{eV}$ for low $\mathrm{Li}^{+}$concentrations 
agrees well with the migration energy barrier $(0.23 \mathrm{eV})$ for a single- $\mathrm{Li}^{+}$adsorbed graphene system. This meets the expectation because $\mathrm{Li}^{+}$arrangements are divergent for the systems with low $\mathrm{Li}^{+}$ concentration. As a result, there is almost no interaction between ions. Thus, $\mathrm{Li}^{+}$migrates like that for a single- $\mathrm{Li}^{+}$adsorbed system. Therefore, the macroscopic migration energy barrier obtained from Arrhenius equation would very close to the value of a single- $\mathrm{Li}^{+}$adsorbed system. With increasing $\mathrm{Li}^{+}$ concentration, the macroscopic migration energy barrier which depends on surrounding environment does increase, which leads to $\mathrm{Li}^{+\prime}$ s diffusion becoming more difficult. It also confirms that the KMC simulation and the method for energy barrier estimation are reasonable and reliable.
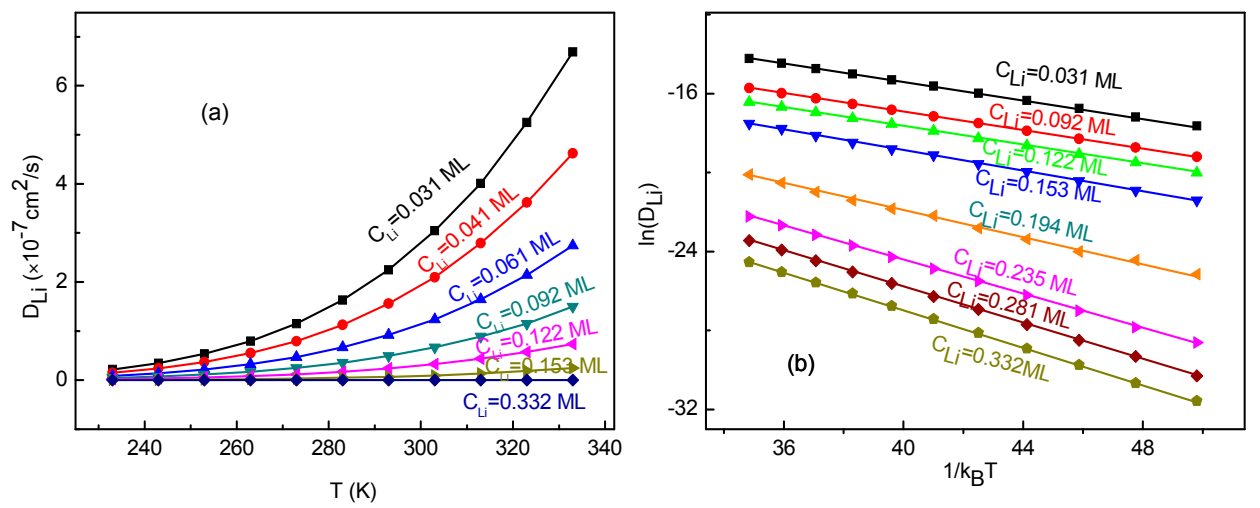

Figure 8. (a) The diffusion coefficient $D_{\mathrm{Li}}$ as a function of temperature $T$; (b) the logarithm of $D_{\mathrm{Li}}$ as a function of $1 /\left(k_{\mathrm{B}} T\right)$, and their fitting lines, for various $\mathrm{Li}^{+}$concentration $C_{\mathrm{Li}}$.

Table 2. The slope $\alpha=-E_{\mathrm{A}}$ and correlation coefficient $r_{2}$ for the linear fitting line between $\ln \left(D_{\mathrm{Li}}\right)$ and $1 /\left(k_{\mathrm{B}} T\right)$, for different $\mathrm{Li}^{+}$concentration $C_{\mathrm{Li}}(\mathrm{ML})$.

\begin{tabular}{ccc}
\hline Concentration $\boldsymbol{C}_{\mathbf{L i}}(\mathbf{M L})$ & Slope ff $=-\boldsymbol{E}_{\mathbf{A}}(\mathbf{e V})$ & Correlation Coefficient $\boldsymbol{r}_{\mathbf{2}}$ \\
\hline 0.031 & $-0.2295 \pm 0.0003$ & 0.9999 \\
0.092 & $-0.2332 \pm 0.0004$ & 0.9999 \\
0.153 & $-0.261 \pm 0.002$ & 0.9995 \\
0.235 & $-0.432 \pm 0.002$ & 0.9998 \\
0.281 & $-0.457 \pm 0.001$ & 0.9999 \\
0.332 & $-0.473 \pm 0.001$ & 0.9999 \\
\hline
\end{tabular}

\section{Conclusions}

In summary, combining first-principle calculations with KMC simulations, we determined the diffusion coefficient of lithium ions in $\mathrm{Li}^{+}$-adsorbed graphene systems. The impacts of $\mathrm{Li}^{+}$ concentration and temperature on the $\mathrm{Li}^{+}$diffusion coefficients were mainly investigated. In the determination of the $\mathrm{Li}^{+}$diffusion coefficient, the interactions between $\mathrm{Li}$ ions were taken into account. In the prediction of energy barriers, we deduce an equation based on those energy barriers obtained from first-principle calculations for single- $\mathrm{Li}^{+}$and two- $\mathrm{Li}^{+}$adsorbed systems to evaluate the energy barriers for $\mathrm{Li}^{+}$-adsorbed systems with more than two $\mathrm{Li}$ ions. The calculated results show that the temperature dependence of diffusion coefficients of $\mathrm{Li}^{+}$fits well to the Arrhenius equation, rather than meeting the equation from the EIS technique, which has usually been used to estimate diffusion coefficients in an experiment. Moreover, our results also show that the $\mathrm{Li}^{+}$concentration dependence of diffusion coefficients is roughly fitted to Equation (15) from the EIS technique in a low concentration region. However, it seriously deviates from Equation (15) in a high concentration region. Our work suggests that Equation (15) could not be simply used to estimate $\mathrm{Li}^{+}$diffusion coefficient for all $\mathrm{Li}^{+}$-adsorbed graphene systems with various $\mathrm{Li}^{+}$concentration. Moreover, these results have an important guiding significance in the experimental determination of the $\mathrm{Li}^{+}$diffusion coefficient. 
Acknowledgments: This work is supported by the National Science Foundation of China $(61574037,61404029$ 11404058, 11274064), Science and Technology Major Projects of Fujian Province (2013HZ0003), Project of Fujian Development and Reform Commission (2013-577), the Natural Science Foundations of Fujian Province of China (2016J05151, 2015J05005, 2016J01011) and Educational Department of Fujian Province, China (JA14092).

Author Contributions: Kehua Zhong, Jian-Min Zhang and Zhigao Huang conceived and designed the models and calculations. Kehua Zhong performed the calculations, data analysis, and wrote this paper. Yanmin Yang, Guigui $\mathrm{Xu}$ performed calculated data analysis. Zhigao Huang revised the paper.

Conflicts of Interest: The authors declare no conflict of interest.

\section{References}

1. Castro Neto, A.; Guinea, F.; Peres, N.; Novoselov, K.; Geim, A. The electronic properties of graphene. Rev. Mod. Phys. 2009, 81, 109-162. [CrossRef]

2. Geim, A.K. Graphene: Status and prospects. Science 2009, 324, 1530-1534. [CrossRef] [PubMed]

3. Novoselov, K.S.; Geim, A.K.; Morozov, S.V.; Jiang, D.; Katsnelson, M.I.; Grigorieva, I.V.; Dubonos, S.V.; Firsov, A.A. Two-dimensional gas of massless dirac fermions in graphene. Nature 2005, 438, 197-200. [CrossRef] [PubMed]

4. Zhang, Y.; Tan, J.W.; Stormer, H.L.; Kim, P. Experimental observation of quantum hall effect and berry's phase in graphene. Nature 2005, 438, 201-204. [CrossRef] [PubMed]

5. Novoselov, K.S.; Geim, A.K.; Morozov, S.V.; Jiang, D.; Zhang, Y.; Dubonos, S.V.; Grigorieva, I.V.; Firsov, A.A. Electric field effect in atomically thin carbon films. Science 2004, 306, 666-669. [CrossRef] [PubMed]

6. Lv, W.; Tang, D.-M.; He, Y.-B.; You, C.-H.; Shi, Z.-Q.; Chen, X.-C.; Chen, C.-M.; Hou, P.-X.; Liu, C.; Yang, Q.-H. Low-temperature exfoliated graphenes: Vacuum-promoted exfoliation and electrochemical energy storage. ACS Nano 2009, 3, 3730-3736. [CrossRef] [PubMed]

7. Yoo, E.; Kim, J.; Hosono, E.; Zhou, H.-S.; Kudo, T.; Honma, I. Large reversible Li storage of graphene nanosheet families for use in rechargeable lithium ion batteries. Nano. Lett. 2008, 8, 2277-2282. [CrossRef] [PubMed]

8. Jang, B.Z.; Liu, C.; Neff, D.; Yu, Z.; Wang, M.C.; Xiong, W.; Zhamu, A. Graphene surface-enabled lithium ion-exchanging cells: Next-generation high-power energy storage devices. Nano. Lett. 2011, 11, 3785-3791. [CrossRef] [PubMed]

9. Lee, E.; Persson, K.A. Li Absorption and intercalation in single layer graphene and few layer graphene by First Principles. Nano. Lett. 2012, 12, 4624-4628. [CrossRef] [PubMed]

10. Wang, G.; Shen, X.; Yao, J.; Park, J. Graphene nanosheets for enhanced lithium storage in lithium ion batteries. Carbon 2009, 47, 2049-2053. [CrossRef]

11. Atabaki, M.M.; Kovacevic, R. Graphene composites as anode materials in lithium-ion batteries. Electron. Mater. Lett. 2013, 2, 133-153. [CrossRef]

12. Su, C.; Bu, X.; Xu, L.; Liu, J.; Zhang, C. A novel $\mathrm{LiFePO}_{4}$ /graphene/carbon composite as a performance-improved cathode material for lithium-ion batteries. Electrochim. Acta 2012, 64, 190-195. [CrossRef]

13. Park, M.; Zhang, X.; Chung, M.; Less, G.B.; Sastry, A.M. A review of conduction phenomena in Li-ion batteries. J. Power Sources 2010, 195, 7904-7929. [CrossRef]

14. Dokko, K.; Mohamedi, M.; Fujita, Y.; Itoh, T.; Nishizawa, M.; Umeda, M.I. Uchida kinetic characterization of single particles of $\mathrm{LiCoO}_{2}$ by AC impedance and potential step methods. J. Electrochem. Soc. 2001, 148, A422-A426. [CrossRef]

15. Montoro, L.A.; Rosolen, J.M. The role of structural and electronic alterations on the lithium diffusion in LixCo ${ }_{0.5} \mathrm{Ni}_{0.5} \mathrm{O}_{2}$. Electrochim. Acta 2004, 49, 3243-3249. [CrossRef]

16. Tang, A.; Wang, X.; Xu, G.; Zhou, Z.; Nie, H. Determination of the chemical diffusion coefficient of lithium in $\mathrm{Li}_{3} \mathrm{~V}_{2}\left(\mathrm{PO}_{4}\right)_{3}$. Mater. Lett. 2009, 63, 1439-1441. [CrossRef]

17. Xia, H.; Lu, L.; Ceder, G. Li diffusion in $\mathrm{LiCoO}_{2}$ thin films prepared by pulsed laser deposition. J. Power Sources 2006, 159, 1422-1427. [CrossRef]

18. Jang, Y., II; Neudecker, B.J.; Dudney, N.J. Lithium diffusion in $\mathrm{Li}_{\mathrm{x}} \mathrm{CoO}_{2}(0.45<\mathrm{x}<0.7)$ intercalation cathodes. Electrochem. Solid-State Lett. 2001, 4, A74-A77.

19. Tang, X.-C.; Li, L.-X.; Lai, Q.-L.; Song, X.-W.; Jiang, L.-H. Investigation on diffusion behavior of $\mathrm{Li}^{+}$in $\mathrm{LiFePO}_{4}$ by capacity intermittent titration technique (CITT). Electrochim. Acta 2009, 54, 2329-2334. [CrossRef] 
20. Liu, G.Q.; Kuo, H.T.; Liu, R.S.; Shen, C.H.; Shy, D.S.; Xing, X.K.; Chen, J.M. Study of electrochemical properties of coating $\mathrm{ZrO}_{2}$ on $\mathrm{LiCoO}_{2}$. J. Alloys Compd. 2010, 496, 512-516. [CrossRef]

21. Cao, Q.; Zhang, H.P.; Wang, G.J.; Xia, Q.; Wu, Y.P.; Wu, H.Q. A novel carbon-coated $\mathrm{LiCoO}_{2}$ as cathode material for lithium ion battery. Electrochem. Commun. 2007, 9, 1228-1232. [CrossRef]

22. Zhu, Y.R.; Xie, Y.; Zhu, R.-S.; Shu, J.; Jiang, L.-J.; Qiao, H.-B.; Yi, T.-F. Kinetic study on $\mathrm{LiFePO}_{4}$-positive electrode material of lithium-ion battery. Ionics 2011, 17, 437-441. [CrossRef]

23. Takami, N.; Satoh, A.; Hara, M.; Ohsaki, T. Structural and kinetic characterization of lithium intercalation into carbon anodes for secondary lithium batteries. J. Electrochem. Soc. 1995, 142, 371-379. [CrossRef]

24. Yu, P.; Popov, B.N.; Ritter, J.A.; White, R.E. Determination of the lithium ion diffusion coefficient in graphite. J. Electrochem. Soc. 1999, 146, 8-14. [CrossRef]

25. Umeda, M.; Dokko, K.; Fujita, Y.; Mohamedi, M.; Uchida, I.; Selman, J.R. Electrochemical impedance study of li-ion insertion into mesocarbon microbead single particle electrode. Part I. Graphitized carbon. Electrochim. Acta 2001, 47, 885-890. [CrossRef]

26. Dokko, K.; Fujita, Y.; Mohamedi, M.; Umeda, M.; Uchida, I.; Selman, J.R. Electrochemical impedance study of Li-ion insertion into mesocarbon microbead single particle electrode: Part II. Disordered carbon. Electrochim. Acta 2001, 47, 933-938. [CrossRef]

27. Shim, J.; Striebel, K.A. Electrochemical Characterization of thermally oxidized natural graphite anodes in Lithium-ion batteries. J. Power Sources 2007, 164, 862-867. [CrossRef]

28. Levi, M.D.; Aurbach, D. The Mechanism of Lithium intercalation in graphite film electrodes in aprotic media. Part 1. High resolution slow scan rate cyclic voltammetric studies and modeling. J. Electroanal. Chem. 1997, 421, 79-88. [CrossRef]

29. Verbrugge, M.W.; Koch, B.J. Electrochemical analysis of lithiated graphite anodes. J. Electrochem. Soc. 2003, 150, A374-A384. [CrossRef]

30. Levi, M.D.; Markevich, E.; Aurbach, D. The effect of slow interfacial kinetics on the chronoamperometric response of composite lithiated graphite electrodes and on the calculation of the chemical diffusion coefficient of Li ions in graphite. J. Phys. Chem. B 2005, 109, 7420-7427. [CrossRef] [PubMed]

31. Yang, H.; Bang, H.J.; Prakash, J. Evaluation of electrochemical interface area and lithium diffusion coefficient for a composite graphite anode. J. Electrochem. Soc. 2004, 151, A1247-A1250. [CrossRef]

32. Tachikawa, H. A direct molecular orbital-molecular dynamics study on the diffusion of the Li ion on a fluorinated graphene surface. J. Phys. Chem. C 2008, 112, 10193-10199. [CrossRef]

33. Das, D.; Kim, S.; Lee, K.-R.; Singh, A.K. Li diffusion through doped and defected graphene. Phys. Chem. Chem. Phys. 2013, 15, 15128-15134. [CrossRef] [PubMed]

34. Uthaisar, C.; Barone, V. Edge effects on the characteristics of Li diffusion in graphene. Nano. Lett. 2010, 10, 2838-2842. [CrossRef] [PubMed]

35. Fan, X.; Zheng, W.T.; Kuo, J.-L. Adsorption and diffusion of Li on pristine and defective graphene. ACS Appl. Mater. Interfaces 2012, 4, 2432-2438. [CrossRef] [PubMed]

36. Zheng, J.; Ren, Z.; Guo, P.; Fang, L.; Fan, J. Diffusion of Li ${ }^{+}$ion on graphene: A DFT study. Applied Surf. Sci. 2011, 258, 1651-1655. [CrossRef]

37. Petrova, N.V.; Yakovkin, I.N.; Ptushinskii, Yu.G. Monte-Carlo simulation of kinetics of $\mathrm{H}_{2}$ molecular adsorption. Surf. Sci. 2002, 497, 349-355. [CrossRef]

38. Becquart, C.S.; Domain, C. An object kinetic Monte Carlo simulation of the dynamics of helium and point defects in tungsten. J. Nucl. Mater. 2009, 385, 223-227. [CrossRef]

39. Du, Y.A.; Rogal, J.; Drautz, R. Diffusion of hydrogen within idealized grains of bcc Fe: A kinetic Monte Carlo study. Phys. Rev. B 2012, 86, 174110. [CrossRef]

40. Kresse, G.; Joubert, D. From ultrasoft pseudopotentials to the projector augmented-wave method. Phys. Rev. B 1999, 59, 1758-1775. [CrossRef]

41. Perdew, J.P.; Burke, K.; Ernzerhof, M. Generalized gradient approximation made simple. Phys. Rev. Lett. 1996, 77, 3865-3868. [CrossRef] [PubMed]

42. Xu, G.G.; Wu, Q.Y.; Chen, Z.G.; Huang, Z.G.; Wu, R.Q.; Feng, Y.P. Disorder and surface effects on work function of Ni-Pt metal gates. Phys. Rev. B 2008, 78, 115420. [CrossRef]

43. Zhong, K.H.; Xu, G.G.; Cheng, Y.M.; Tang, K.Q.; Chen, Z.G.; Huang, Z.G. A novel spin modulation of work function for $\mathrm{C}$ adsorbed $\mathrm{Cr} / \mathrm{Fe}(001)$ metal gate. AIP Adv. 2012, 2, 042134. [CrossRef] 
44. Zhong, K.H.; Xu, G.G.; Zhang, J.-M.; Huang, Z.G. Effects of strain on effective work function for $\mathrm{Ni}^{2} \mathrm{HfO}_{2}$ interfaces. J. Appl. Phys. 2014, 116, 063707. [CrossRef]

45. Xu, G.G.; Wu, Q.Y.; Chen, Z.G.; Huang, Z.G.; Feng, Y.P. Effects of surface alloying and orientation on work function of MoTa metal gate. J. Appl. Phys. 2009, 106, 043708. [CrossRef]

46. Zhang, J.-M.; Ming, W.; Huang, Z.G.; Liu, G.-B.; Kou, X.; Fan, Y.; Wang, K.L.; Yao, Y. Stability, electronic, and magnetic properties of the magnetically doped topological insulators $\mathrm{Bi}_{2} \mathrm{Se}_{3}, \mathrm{Bi}_{2} \mathrm{Te}_{3}$, and $\mathrm{Sb}_{2} \mathrm{Te}_{3}$. Phys. Rev. B 2013, 88, 235131. [CrossRef]

47. Perdew, J.P.; Chevary, J.A.; Vosko, S.H.; Jackson, K.A.; Pederson, M.R.; Singh, D.J.; Fiolhais, C. Atoms, molecules, solids, and surfaces: Applications of the generalized gradient approximation for exchange and correlation. Phys. Rev. B 1992, 46, 6671-6687. [CrossRef]

48. Sevinçli, H.; Topsakal, M.; Durgun, E.; Ciraci, S. Electronic and magnetic properties of 3D transition-metal atom adsorbed graphene and graphene nanoribbons. Phys. Rev. B 2008, 77, 195434. [CrossRef]

49. Larsson, M.I.; Sabiryanov, R.F.; Cho, K.; Clemens, B.M. Nanopatterning of periodically strained surfaces: Predictive kinetic Monte Carlo simulation study. J. Appl. Phys. 2003, 94, 3470-3484. [CrossRef]

50. Ramanarayanan, P.; Cho, K.; Clemens, B.M. Effect of composition on vacancy mediated diffusion in random binary alloys: First principles study of the $\mathrm{Si}_{1-x} \mathrm{Ge}_{\mathrm{x}}$ system. J. Appl. Phys. 2003, 94, 174-185. [CrossRef]

51. Moon, J.; Lee, B.; Cho, M.; Cho, K. Ab initio and kinetic Monte Carlo simulation study of lithiation in crystalline and amorphous silicon. J. Power Sources 2014, 272, 1010-1017. [CrossRef]

52. Yang, X.; Hassanein, A. Kinetic Monte Carlo simulation of hydrogen diffusion on tungsten reconstructed (001) surface. Fusion Eng. Des. 2014, 89, 2545-2549. [CrossRef]

53. Takachi, M.; Fukuzumi, Y.; and Moritomo, Y. Concentration dependence of $\mathrm{Li}^{+} / \mathrm{Na}^{+}$diffusion in manganese hexacyanoferrates. Jpn. J. Appl. Phys. 2016, 55, 067101. [CrossRef]

54. Pollak, E.; Geng, B.; Jeon, K.J.; Lucas, I.T.; Richardson, T.J.; Wang, F.; Kostecki, R. The interaction of Li ${ }^{+}$with single-layer and few-layer graphene. Nano. Lett. 2010, 10, 3386-3388. [CrossRef] [PubMed]

55. Malyi, O.I.; Tan, T.L.; Manzhos, S. A comparative computational study of structures, diffusion, and dopant interactions between Li and $\mathrm{Na}$ insertion into Si. Appl. Phys. Express 2013, 6, 027301. [CrossRef]

56. Fan, X.; Zheng, W.T.; Kuo, J.-L.; Singh, D.J. Adsorption of single Li and the formation of small Li clusters on graphene for the anode of lithium-ion batteries. ACS Appl. Mater. Interfaces 2013, 5, 7793-7797. [CrossRef] [PubMed]

57. Persson, K.; Sethuraman, V.A.; Hardwick, L.J.; Hinuma, Y.; Meng, Y.S.; van der Ven, A.; Srinivasan, V.; Kostecki, R.; Ceder, G. Lithium diffusion in graphitic carbon. J. Phys. Chem. Letts. 2010, 1, 1176-1180. [CrossRef]

58. Piao, T.; Park, S.M.; Doh, C.H.; Moonb, S.I. Intercalation of Lithium ions into graphite electrodes studied by AC impedance measurements. J. Electrochem. Soc. 1999, 146, 2794-2798. [CrossRef]

59. Wu, S.L.; Zhang, W.; Song, X.Y.; Shukla, A.K.; Liu, G.; Battaglia, V.; Srinivasan, V. High rate capability of $\mathrm{Li}\left(\mathrm{Ni}_{1 / 3} \mathrm{Mn}_{1 / 3} \mathrm{Co}_{1 / 3}\right) \mathrm{O}_{2}$ electrode for Li-ion batteries. J. Electrochem. Soc. 2012, 159, A438-A444. [CrossRef]

60. Amina, R.; Chianga, Y.M. Characterization of electronic and ionic transport in $\mathrm{Li}_{1-\mathrm{x}} \mathrm{Ni}_{0.33} \mathrm{Mn}_{0.33} \mathrm{Co}_{0.33} \mathrm{O}_{2}$ (NMC333) and $\mathrm{Li}_{1-\mathrm{x}} \mathrm{Ni}_{0.50} \mathrm{Mn}_{0.20} \mathrm{Co}_{0.30} \mathrm{O}_{2}$ (NMC523) as a function of Li content. J. Electrochem. Soc. 2016, 163, A1512-A1517. [CrossRef]

61. Chou, C.Y.; Hwang, G.S. On the origin of the significant difference in lithiation behavior between silicon and germanium. J. Power Sources 2014, 263, 252-258. [CrossRef]

62. Yang, X.-Y.; Lu, Y.; Zhang, P. The temperature-dependent diffusion coefficient of helium in zirconium carbide studied with first-principles calculations. J. Appl. Phys. 2015, 117, 164903. [CrossRef]

63. Bouar, Y.L.; Soisson, F. Kinetic pathways from embedded-atom-method potentials: Influence of the activation barriers. Phys. Rev. B 2002, 65, 094103. [CrossRef]

(C) 2017 by the authors. Licensee MDPI, Basel, Switzerland. This article is an open access article distributed under the terms and conditions of the Creative Commons Attribution (CC BY) license (http:/ / creativecommons.org/licenses/by/4.0/). 